\title{
Moral injury and the COVID-19 pandemic: reframing what it is, who it affects and how care leaders can manage it
}

\author{
Suzanne Shale ${ }^{1,2}$
}

'Oxleas NHS Foundation Trust, Dartford, UK

${ }^{2}$ Department of Security and Crime Science, University College London, London, UK

\section{Correspondence to}

Dr Suzanne Shale, Oxleas NHS Foundation Trust, Dartford,

Kent, UK;

suzanne.shale@clearer-thinking. co.uk

Received 11 June 2020 Revised 25 June 2020 Accepted 29 June 2020 Published Online First 17 July 2020
Check for updates

(C) Author(s) (or their employer(s)) 2020. No commercial re-use. See rights and permissions. Published by BMJ.

To cite: Shale S. BMJ Leader 2020:4:224-227.
The term moral injury has achieved widespread circulation among care leaders during the pandemic, and has been influential in prompting care providers to give fresh consideration to the psychological support available to staff. ${ }^{12}$ The notion of moral injury that has come to prominence is one that some label 'occupational moral injury'. This arises during work such as armed combat or emergency response when people carry out, fail to prevent, or become aware of, human actions that violate deep moral commitments. Occupational moral injury is often associated with psychological distress, and moral responses including guilt, anger and disgust. ${ }^{3}$

Here I draw attention to a broader notion of moral injury found in moral philosophy. In this version, a moral wound can be experienced by anyone. It arises from sources that include injustice, cruelty, status degradation and profound breaches of moral expectations. The moral-philosophical version of moral injury associates it with moral and psychological anguish, and feelings such as bewilderment, humiliation and resentment. According to this formulation of moral injury, it could affect patients, service users, families and loved ones as well as care staff.

Experiences of moral injury among the wider public, as well as staff, will call for attention from care leaders long after the pandemic surge.

\section{UNDERSTANDING MORAL INJURY}

Prior to the pandemic, care leaders did not commonly use the term 'moral injury'. They most likely use it now to refer to 'occupational moral injury'. However, many will recognise moral injury in the moral-philosophical sense from their ordinary experience of leadership. This is because it is conceptually grounded in recognisable moral behaviours. Care leaders may already possess an implicit understanding of how this type of moral injury arises, and tacit knowledge of what to do about it. By making the implicit explicit, this commentary aims to support care leaders to respond well to forthcoming challenges.

\section{Trauma-based accounts of moral injury}

The notion of occupational moral injury that is prevalent in the clinical literature originated in therapy for US war veterans. ${ }^{45}$ Shay's insight, as a psychiatrist, was that some veterans experienced traumatic existential crises that differed in important ways from post-traumatic stress disorder (PTSD) as then defined. Shay viewed veterans' suffering as a 'character wound' associated with annihilation of trust $^{6}$ that undermined their personal moral foundations. Shay appears to have been the first to use the term moral injury in a therapeutic context, defining it by reference to how it arose in combat situations: 'a betrayal of what's right by someone who holds legitimate authority in a high stakes situation'. ${ }^{7}$ Litz et al subsequently proposed a wider definition of moral injury, 'perpetrating, failing to prevent, bearing witness to or learning about acts that transgress deeply held moral beliefs and expectations.' ${ }^{8}$ This definition has been widely adopted in studies of public service professions. ${ }^{9}$

The heightened interest in a conception of moral injury derived from combat experience is consistent with some familiar rhetorical tropes of the pandemic: talk of fight, battle, front lines, winning the war and circumstances said to be unprecedented. Some of this is justified, and attentiveness to the psychological well-being of care providers is to be welcomed without reserve. But to view moral injury as a newly discovered phenomenon that primarily affects professionals is to overlook first, how moral injury befalls citizens; second, a history of lived experiences of moral injury in care organisations; and third, the understanding care leaders already possess of how to prevent and address moral injury.

As Papadopoulos has written, those who work with people affected by human conflict and other catastrophes know all too well that ordinary citizens find life-changing adversity deeply morally disturbing. "Troubled by the unpredictable and catastrophic turn of events, and facing the lifeshattering consequences of the experienced adversities, they are shaken to the core of their being, and in deep anguish they struggle to make sense of what has befallen them and to reassess most aspects of their lives". 10

Adversity has the potential to become morally injurious because, as we are told by those who have experienced it, it shakes people to their foundations. It feels as though 'the rug has been pulled from underneath my feet', that 'my whole world has been turned upside down'. Moral assumptions that ground us, expectations about what and who we can rely on, are placed in jeopardy. Such citizen experience of moral injury is a dimension to human tragedy not quite captured in narrow conceptions of trauma, just as veterans' experiences of moral injury could not be captured by the terminology of PTSD. 
Care leaders most frequently encounter citizen experiences of moral injury while responding to care harm. Patients who have suffered serious adverse events, loved ones affected by the harm done to the patient, and loved ones bereaved by unexpected death in a care setting, often express the sentiments in the paragraph above. Moreover, there is growing awareness among care providers of the 'second harm' inflicted on patients and loved ones by defensive, dishonest, unempathetic or otherwise unhelpful responses to adverse events in care. ${ }^{11}$ This notion of second harm is most often couched in psychological terms, but when we listen to the ways patients describe it (disorientation, disbelief, a sense of betrayal, loss of trust in institutions and processes for instance $)^{12}$ the impact is clearly akin to the moral injury that Papadopoulos recognises in other traumatic events.

\section{Moral and philosophical accounts of moral injury}

Accounts of moral injury based in psychology of trauma date back several decades. However, moral philosophers find a recognisable concept of moral injury in the eighteenth century works of Bishop Joseph Butler and Adam Smith. ${ }^{13}{ }^{14}$ Both Butler and Smith associated moral injury with citizens' experiences of cruelty and injustice, and they argued that an attitude of resentment was a morally important form of anger that arose in response. Butler's insights on moral injury and resentment were recalled some two centuries later by Hampton and Murphy. These modern authors viewed moral injury as actions that profoundly insult or degrade others, thus damaging 'self-respect, respect for others as moral agents, and respect for the rules of morality or the moral order'. ${ }^{15}$ More recently, philosopher Margaret Walker provided a contemporary account of moral injury which I draw on here. ${ }^{6}$

It is helpful first to understand how so-called 'normative expectations' underpin our day to day moral life, making trustbased moral relationships possible. Normative expectations are, broadly, beliefs about what people should do combined with predictions about what they will do. They are both moral (should) and predictive (will) expectations. Citizens who trust care providers have a normative expectation that they should keep them from harm, and also that they will keep them from harm. Staff who trust care providers have a normative expectation that employers should provide appropriate personal protective equipment (PPE), and that they will provide appropriate PPE. When normative expectations are mostly met, individuals and communities are able to have trust, confidence and hope in the future.

Violation of normative expectations can invoke strong emotions, notably the attitude of resentment described by Butler and Smith. Resentment can be understood as a 'kind of accusing anger at something done', in particular when a thing done appears to be a significant violation without any adverse consequences for the violator. ${ }^{6}$ Resentment directed towards those with the authority to take a situation in hand is a form of 'moral address', a demand to restore respect for breached normative expectations. Resentment is uncomfortable, but reminds us that moral relations are in need of repair. To return to the example of care harm, resentment does not automatically follow in the wake of harm itself. Rather, resentment more often arises when harmed patients or their loved ones apprehend that their normative expectations of respect, truthfulness or meaningful remedial action are not being met. It is not the initial harm, but the violated expectations about what constitutes a proper response to it, that disrupt moral repair.

All in all, resentment is valuable because it helps to sustain moral community by triggering a response to breaches of normative expectation. But resentment can also be destructive when it festers in individuals and institutions, mutating into cynical withdrawal or angry retaliation. When we learn that we cannot rely on each other, or authority, to uphold fundamental normative expectations we suffer a loss of trust and confidence in (among other things) people, principles, rules, processes and institutions.

The common thread that binds trauma-based theories of moral injury and moral-philosophical theories of moral injury is, therefore, that both emphasise how we build a stable foundation for our psychological, emotional and social existence through being able to rely, more or less, on our moral expectations being met. Unfortunately, we do not always know what our own, or others', normative expectations are until the point that they are breached. Even then, feelings of resentment are merely the clue that underlying expectations require examination.

Although the terms moral injury and moral repair may not have been widely used in care leadership circles in the past, it will hopefully be apparent that the experiences they refer to have in fact been an ordinary part of care leadership. Potentially morally injurious circumstances arise whenever patients are harmed; when staff are poorly treated for raising concerns; when patients or staff suffer discriminatory behaviour; when inadequate resources put staff and patients at risk; when there is avoidance of accountability at the highest level of public institutions and so on.

Before going further, we should note that on any account of it, leaders may potentially be the commissioner or the subject of moral injury, or the author of moral repair. In future months and years, care leaders may find themselves occupying any, or indeed all, of these positions.

\section{WHAT MIGHT BE POTENTIAL SOURCES OF MORAL INJURY FOLLOWING THE PANDEMIC?}

I was writing this commentary during a period of public outrage that started with the behaviour of the UK Prime Minister's special advisor Dominic Cummings and was shortly followed by the police killing of Black US citizen George Floyd. These events afford us insight into three notable sources of moral injury, analysed below. It is important to state that it is not possible, within the scope of this commentary, to do justice to the meaning of the protests that followed George Floyd's death.

Situations in which it is not possible to fulfil cherished moral commitments are the first source of moral injury. Cummings was widely perceived to have violated lockdown by driving from London to Durham when infected and taking his family on an excursion during his recuperation. This news was met by an outpouring of grief and anger. It came from people not allowed to be with parents, children and partners when they died; unable to attend or invite people to funerals; not permitted to be present at births; unable to greet newborns, or to visit to support new mothers. It was not just those directly affected who expressed outrage, but many who empathised with them and who had themselves followed the rules.

Preventing the spread of coronavirus needed millions of people to treat the good of strangers as more important than their own preferences, and in some cases even more important than obligations of love and care they felt they owed to those close to them. People who made this sacrifice can rightly claim it as a profoundly moral act, but it is not without cost. Being prevented from doing what we normally believe to be right, when deeply felt needs and obligations are calling us to do so, is morally injurious. For citizens, being prevented from meeting fundamental 
moral commitments associated with birth, love and death is akin to the moral injury experienced by care workers when they are unable to provide the care they believe they should. For a man who asked others to set their own moral commitments aside, to then insist he was morally justified in not making the same sacrifice, adds insult to injury.

Turning now to George Floyd's death, this violated basic normative expectations of police behaviour including that they should act justly towards every citizen, irrespective of race. The brutality of his treatment prompts us to recall that cruelty and injustice were at the heart of Bishop Butler and Adam Smith's understanding of moral injury. And, the Black Lives Matter movement highlights the many ways systemic racial inequality injures BAME (Black, Asian and Minority Ethnic) people, through showing lack of respect for them and for moral equality. This type of abuse is central to Hampton and Murphy's conception of moral injury.

Finally, resentment in both these cases has served to call attention to unpunished violations of significant moral expectations. In Cummings' case, he has apparently broken morally demanding rules and subsequently escaped without censure. In Floyd's case, widespread expressions of resentment were a 'moral address' to authorities to bring Floyd's killers, and other police officers, to account.

How might identifying these sources of moral injury help leaders prepare for the moral injury that may emerge following the pandemic? Drawing on Walker, ${ }^{6}$ I have categorised potentially morally injurious problems below into harms, losses, exploitation and demotions of others' status. The issues I flag are all breaches of normative expectation. Whether they turn out to inflict deep moral injuries will depend to some extent on whether they are met with early moral repair. So, following this list, I turn to moral repair.

\section{Harms}

- Nosocomial infection with coronavirus.

- Additional non-COVID-19 deaths following disruption of normal care pathways, for example, diabetes, sepsis, asthma and renal failure.

- Physical and/or mental harm following delay or cancellation of treatment during the pandemic, and from long waiting lists once non-urgent, non-COVID-19 treatment restarts.

- Injury to the physical or mental health of long-term care residents (older people, people with learning disability and so on) during the lockdown.

- Disproportionate impact of COVID-19 on BAME staff and communities.

\section{Losses}

- Psychological distress among families not permitted to attend deaths, births and so on during the surge.

- Psychological distress in staff who have foregone their own family contacts to promote infection control; witnessed repeated bereavement and grief; or who have not been able to provide care they thought patients deserved.

- Withdrawal or reduction in services such as mental health support, face-to-face appointments, or care (such as hydrotherapy) for people deemed able to get by without it.

- Additional loss of personal freedom for some (eg, people with learning disabilities or mental health inpatients) owing to difficulties arranging leave, exercise and so on.
- Impact on residents, staff and families should private residential care providers become unviable owing to financial and other pressures.

\section{Exploitation}

- Colleagues perceived to be 'free riders' or to have 'not pulled their weight' during the pandemic, for example, abusing self-isolation rules or refusing to alter working patterns.

- Leaders using the pandemic as a cover to make contentious changes in service provision, such as closing emergency departments.

\section{Demotions}

- Exclusion of patients' families from care and decisionmaking at end of life during the pandemic.

- People who need care for long-term conditions perceiving they have been treated as a lower priority during the pandemic than people with COVID-19.

- Patient and lay representatives excluded from system recovery planning or consultations around service reconfiguration.

\section{RESPONDING TO MORAL INJURY WITH MORAL REPAIR}

Both Kaplan's 'law of the instrument' (to a man with a hammer, everything looks like a nail) and the French concept of 'deformation professionelle' lead us to expect that adherents to a traumabased conception of moral injury will favour psychological interventions, while adherents to a moral conception will favour actions based in moral repair. It would not be helpful to place these two modes in opposition, and indeed one of the reasons for writing this commentary is the conviction that each should inform the other. Greenberg and Tracy have written in this journal about a preventive, psychological approach to supporting staff at risk of occupational moral injury. They advocate reinforcing social bonds between colleagues and supervisors, meeting basic staff needs, being alert to early signs of distress and avoiding 'medicalisation' of uncomfortable responses to trauma. ${ }^{16}$ Moral repair, which can be preventive as well as reparative, aims to re-establish a sense of moral equilibrium within individuals and between people. The principles outlined below seek to restore trust, confidence and hope. ${ }^{6}$

As I have discussed in detail elsewhere, theorists and practitioners view seven acts of acknowledgement as central. ${ }^{17} 18$ Acknowledgement is a combination of deep listening, altered understanding and mutually agreed reparative action.

1. Acknowledging an injured party as a moral equal. Moral repair will not succeed if one party is placed in an inferior moral position, seen as having less right to define the situation than those in authority. When people are told by authority 'this is how we see it and how we see it is what counts', they are not being treated as moral equals.

2. Acknowledging the authority of shared norms. Moral repair requires that we recognise the existence of shared norms, make clear that these norms remain important even though they may have been violated, and treat them as action guiding.

3. Acknowledging injury. A suitable context must be created in which the nature of (moral) injury can be spoken of, explained, heard and understood. Attending to the testimony of those affected by moral injury is critical.

4. Acknowledging responsibility. Moral repair requires that those who are truly responsible for something acknowledge that responsibility. This is not the same as laying blame. In acknowledging responsibility, the person or institution recog- 
nises that others have placed reliance on them and have been let down. Acknowledging responsibility reinforces the view that the norms are valid, and it is reasonable to rely on them.

5. Acknowledging that remedy is due, and that the injured party may define what is owed. The first part of this can be difficult, and the second part even more challenging. Failure to acknowledge that remedy is due is, to paraphrase Archbishop Desmond Tutu, equivalent to saying sorry for stealing your pen and then refusing to give it back. Moral repair obliges us to ask what we can do to rectify the wrong. In cases of medical harm we cannot change the past, and patients know this. What they ask us to do is take steps to prevent the same thing happening again. The remedy of future prevention has, unfortunately, been somewhat debased by organisations claiming to have 'learnt' from events while not implementing effective improvement.

6. Acknowledging righteous anger, or other negative feelings, in those who have been injured. While most will recognise the validity of resentment, anger, hurt and so on, it may need to be acknowledged for much longer than the commissioner of the injury feels comfortable with. It is common to complain that someone or some group now needs 'to move on'. It is not for anyone who has (morally) injured another to determine the timescale for recovery or restoration.

7. Acknowledging that in injuring another, we should experience sorrow and regret. This is often viewed as a requirement for apologies. It is more than that. This is not about words but making it apparent that there is genuine sorrow and regret, perhaps remorse for moral injury one has inflicted.

\section{CONCLUSION}

The term 'moral injury' was not widely used by care leaders before the pandemic, nor has the term moral repair been in leadership common parlance. However, even if the terminology is relatively new, examples of moral injury and practices of moral repair will be recognisable to many.

Coronavirus has presented leaders with exceptional challenges. Some leaders may feel that they themselves have suffered moral injury during the pandemic, according to any of the definitions. Some will be concerned that they have inadvertently commissioned it. And some may feel daunted at the prospect of having to repair it. The same can also be said about the grievous patterns of racial inequality that have been exposed both by COVID-19 and the recent protests.

Drawing attention to potential moral injuries more farreaching than those already well-rehearsed may not be welcome at a time when care leaders face extraordinary clinical and organisational demands. But when moral injuries do not receive due attention, they weigh down both people and institutions. The pandemic may be unprecedented, but moral injury in care organisations is not. An important message to take from this commentary is that within the community of care leaders, there are those who understand, at least implicitly, how moral injury is caused; and there is considerable scope to draw on and learn from previous experiences of attempting moral repair.

Twitter Suzanne Shale @ethicsconsult

Contributors SS is the sole author.

Funding The authors have not declared a specific grant for this research from any funding agency in the public, commercial or not-for-profit sectors.

Competing interests SS works as an independent ethics consultant providing services to the NHS, public bodies, private health providers and not-for-profit organisations. She chairs the charity Action against Medical Accidents.

Patient consent for publication Not required.

Provenance and peer review Commissioned; externally peer reviewed.

This article is made freely available for use in accordance with BMJ's website terms and conditions for the duration of the covid-19 pandemic or until otherwise determined by BMJ. You may use, download and print the article for any lawful, non-commercial purpose (including text and data mining) provided that all copyright notices and trade marks are retained.

\section{REFERENCES}

1 Greenberg N, Docherty M, Gnanapragasam S, et al. Managing mental health challenges faced by healthcare workers during covid-19 pandemic. BMJ 2020;368:m1211.

2 Williamson V, Murphy D, Greenberg N. COVID-19 and experiences of moral injury in front-line key workers. Occup Med 2020. doi:10.1093/occmed/kqaa052. [Epub ahead of print: 02 Apr 2020]

3 Williamson V, Stevelink SAM, Greenberg N. Occupational moral injury and mental health: systematic review and meta-analysis. Br J Psychiatry 2018;212:339-46.

4 Shay J. Achilles in Vietnam: combat trauma and the undoing of character. Simon and Schuster, 2010.

5 Shay J. Odysseus in America: combat trauma and the trials of homecoming. Simon and Schuster, 2003.

6 Walker MU. Moral repair: reconstructing moral relations after wrongdoing. Cambridge: Cambridge University Press, 2006.

7 Shay J. Moral injury. Psychoanal Psychol 2014;31:182-91.

8 Litz BT, Stein N, Delaney E, et al. Moral injury and moral repair in war veterans: a preliminary model and intervention strategy. Clin Psychol Rev 2009;29:695-706.

9 Haight W, Sugrue E, Calhoun M, et al. A scoping study of moral injury: identifying directions for social work research. Child Youth Serv Rev 2016;70:190-200.

10 Papadopoulos RK. Moral injury and beyond: understanding human anguish and healing traumatic wounds. Milton Park, Abingdon, Oxon; New York, NY: Routledge, 2020.

11 Ottosen MJ, Sedlock EW, Aigbe AO, et al. Long-term impacts faced by patients and families after harmful healthcare events. J Patient Saf 2018. doi:10.1097/ PTS.0000000000000451. [Epub ahead of print: 17 Jan 2018].

12 Kenward L. When the healthcare system causes harm. Therapy Today 2016;27:34-6.

13 Butler J. Fifteen sermons preached at the rolls chapel: Botham, 1726.

14 Smith A. The theory of moral sentiments. DD Raphael \& AL Macfie Liberty Fund, 1759.

15 Murphy JG, Hampton J. Forgiveness and mercy. Cambridge University Press, 1990

16 Greenberg N, Tracy D. What healthcare leaders need to do to protect the psychological well-being of frontline staff in the COVID-19 pandemic. BMJ 2020.

17 Shale S. Moral leadership in medicine: building ethical healthcare organizations. Cambridge University Press, 2012.

18 Anderson-Wallace M, Shale S. Restoring trust: what is 'quality' in the aftermath of healthcare harm? Clin Risk 2014;20:16-18. 